\title{
FAKTOR BERALIHNYA TENAGA KERJA ANAK PETANI KE SEKTOR NON-PERTANIAN DI DESA TREMAN KECAMATAN KAUDITAN KABUPATEN MINAHASA UTARA
}

\author{
Aprilia Deasi Wehantouw \\ Elsje Pauline Manginsela \\ Vicky R. B. Moniaga
}

\begin{abstract}
This study aims to increase the knowledge regarding determinant factors causes the shift of youth labor as farmers' children to non-agricultural sector. The location of the research was conducted in Treman Village, Kauditan District, North Minahasa Regency. The study was conducted from January to June 2018. The data used were primary and secondary data. Number of child farmers as the selected respondents are 18 people representing XVIII Jaga by using purposive sampling method. Data analysis used descriptive qualitative analysis in the form of tables and simple quantitative calculations. The results showed that there are two groups of factors causing the shift of child labor of farmers to non-agricultural sector. The first group is the push factor which consists of (1) the conversion of agricultural land to non-agriculture such as the displacement of agricultural land for the construction of buildings and roads which result in the narrowing of the availability of working and working fields, (2) lack of understanding and willingness to work in the agricultural sector. While the second group is the pull factor, consisting of (1) the wage / salary rate in the agricultural sector is lower than wages in the non-agricultural sector. (2) Peasant children's views on employment in non-agricultural and agricultural sectors. There are four views expressed by the child farmers are: $a$. work in accordance with the field of science related to non-agriculture because according to the last education that has been taken, $b$. working in the non-agricultural sector is more appreciated and raises social status, $c$. want to improve working experience in non-agricultural sector, $d$. better working conditions in non-agriculture than the conditions of employment in agriculture. (3) the more open the opportunities for business and work and the more choices of types of business and work available in the nonagricultural sector than in the agricultural sector.*eprm*.
\end{abstract}

Keywords: labor, child farmers, non-agricultural sector, Treman Village, Kauditan Sub-District, North Minahasa Regency

\begin{abstract}
ABSTRAK
Penelitian ini bertujuan untuk mengetahui faktor penentu apa saja yang menyebabkan beralihnya tenaga kerja anak petani ke sektor non-pertanian. Lokasi penelitian dilakukan di Desa Treman, Kecamatan Kauditan, Kabupaten Minahasa Utara. Penelitian dilakukan dari bulan Januari sampai bulan Juni 2018. Data yang digunakan adalah data primer dan data sekunder. Jumlah anak petani sebagai responden yang di pilih yaitu 18 orang yang mewakili XVIII Jaga dengan menggunakan metode pengambilan sampel secara sengaja (purposive sampling). Analisis data dalam penelitian ini menggunakan analisis deskriptif kualitatif dalam bentuk tabel serta perhitungan kuantitatif sederhana. Hasil penelitian menunjukkan bahwa terdapat 2 kelompok faktor penyebab beralihnya tenaga kerja anak petani ke sektor non-pertanian. Kelompok pertama yaitu faktor pendorong yang terdiri atas (1) alih fungsi lahan pertanian ke non-pertanian seperti tergusurnya lahan pertanian untuk pembangunan gedung dan jalan yang mengakibatkan semakin sempitnya ketersediaan lapangan berusaha dan bekerja, (2) kurangnya pemahaman dan kemauan bekerja di sektor pertanian. Sedangkan kelompok kedua yaitu faktor penarik, terdiri atas (1) tingkat upah/gaji di sektor pertanian lebih rendah daripada upah di sektor non-pertanian. (2) Pandangan anak petani terhadap pekerjaan di sektor non-pertanian dan pertanian. Terdapat empat pandangan yang dikemukakan oleh anak petani yaitu: a. bekerja sesuai pada bidang ilmu yang terkait dengan non-pertanian karena sesuai dengan pendidikan terakhir yang telah ditempuh, b. bekerja pada sektor non-pertanian lebih dihargai dan menaikkan status sosial, c. ingin meningkatkan pengalaman bekerja di sektor non-pertanian, $d$. kondisi pekerjaan yang lebih baik dibandingkan kondisi pekerjaan di bidang pertanian. (3) semakin lebih terbuka peluang berusaha dan bekerja serta semakin lebih banyak pilihan jenis usaha dan kerja yang tersedia di sektor non-pertanian dibandingkan pada sektor pertanian. *eprm*.
\end{abstract}

Kata kunci: tenaga kerja, anak petani, sektor non-pertanian, Desa Treman, Kecamatan Kauditan, Kabupaten Minahasa Utara 


\section{PENDAHULUAN}

\section{Latar Belakang}

Pertanian, merupakan kegiatan manusia dalam membuka lahan dan bercocok tanam dengan berbagai jenis tanaman diantaranya tanaman semusim, tanaman tahunan, tanaman pangan dan tanaman non-pangan. Pertanian dapat mengandung dua arti yaitu: (1) Pertanian dalam arti sempit atau sehari-hari dapat diartikan sebagai kegiatan bercocok tanam, dan (2) Pertanian dalam arti luas diartikan sebagai kegiatan yang menyangkut proses produksi menghasilkan bahan-bahan kebutuhan manusia yang dapat berasal dari tumbuhan maupun hewan yang disertai dengan usaha untuk memperbaharui, memperbanyak (reproduksi) dan mempertimbangkan faktor ekonomis (Suratiyah, 2015).

Dwi Andreas Santosa (Kompas 20 Juni 2018), yang merupakan Ketua Asosiasi Bank Benih dan Teknologi Tani Indonesia (AB2TI), menyatakan bahwa kesejahteraan petani belum sesuai dengan harapan petani, hal ini diperburuk lagi dengan adanya konversi lahan sehingga banyak yang petani tersingkir. Tambahan pula profesi petani sudah tidak menarik bagi anak muda di desa karena mereka lebih tertarik pada perkembangan industri dan jasa. Lebih lanjut anak petani yang tidak lagi tertarik pada pekerjaan di sektor pertanian yang mengakibatkan kelompok petani saat ini lebih didominasi oleh petani usia lanjut. Terjadinya pergeseran tenaga kerja pertanian ke sektor non-pertanian dari suatu Negara menyebabkan penurunan jumlah tenaga kerja pada sektor pertanian (Alagukannan dkk, 2016) yang dapat mengancam masa depan sektor pertanian suatu bangsa (Singh \& Gupta, 2014).

Sulawesi Utara adalah salah satu provinsi yang berada di Indonesia dan juga merupakan salah satu provinsi yang memiliki hasil produksi di sektor pertanian yang termasuk tinggi. Namun hasil produksi tidak menjamin kesejahteraan masyarakat, karena harga jual hasil pertanian tidak menentu dan permintaan terhadap hasil panen tidak menentu juga turut berperan dalam menentukan tingkat kesejahteraan masyarakat. Kebutuhan hidup yang menjadi tuntutan terhadap individu atau kelompok (keluarga) agar dapat memiliki kehidupan yang lebih layak, menjadikan pekerjaan sebagai pengantara untuk tercapainya kesejahteraan hidup.
Desa Treman, Kecamatan Kauditan Kabupaten Minahasa Utara merupakan desa yang menjadi lokasi penelitian ini karena terdapat kecenderungan anak petani yang beralih pekerjaan ke sektor pertanian. Sehingga perlu diketahui apa penyebab anak petani tidak tertarik menjadi petani.

\section{Faktor-faktor Beralihnya Tenaga Kerja Anak Petani Ke Sektor Non-Pertanian}

Menurut Soekanto (2017), apabila hendak ditinjau sebab urbanisasi, maka harus diperhatikan dua sudut, yaitu:

a. Faktor yang mendorong penduduk desa untuk meninggalkan daerah kediamannya (push factor); dan

b. Faktor kota yang menarik penduduk desa untuk pindah dan menetap di kota-kota (pull factor).

Bila dianalisis, sebab-sebab pendorong orang desa meninggalkan tempat tinggalnya secara umum adalah sebagai berikut.

a. Di desa lapangan kerja pada umumnya kurang. Pekerjaan yang dapat dikerjakan adalah pekerjaan yang semuanya menghadapi berbagai kendala seperti irigasi yang tak memadai atau tanah yang kurang subur serta terbatas. Keadaan tersebut menimbulkan pengangguran tersamar disguised unemploymet.

b. Penduduk desa, terutama kaum muda mudi, merasa tertekan oleh adat istiadat yang mengakibatkan cara hidup yang monoton. Untuk mengembangkan pertumbuhan jiwa, banyak yang pergi ke kota.

c. Di desa tidak banyak kesempatan untuk menambah pengetahuan. Oleh sebab itu, banyak orang yang ingin maju meninggalkan desa

d. Rekreasi yang merupakan salah satu faktor penting di bidang spiritual kurang sekali dan kalau juga ada, perkembangan sangat lambat.

e. Bagi penduduk desa yang mempunyai keahlian lain selain bertani seperti misalnya kerajinan tangan, tentu mengingini pasaran yang lebih luas bagi hasil produksinya. Ini tidak mungkin didapatkan di desa.

Sebaliknya akan dijumpai pula beberapa faktor penarik dari kota, antara lain sebagai berikut.

a. Penduduk desa kebanyakan mempunyai anggapan bahwa di kota banyak pekerjaan serta banyak penghasilan (uang). Karena sirkulasi uang di kota jauh lebih cepat, lebih besar, dan lebih banyak, maka secara relatif lebih mudah mendapatkan uang daripada di desa. 
b. Di kota lebih banyak kesempatan mendirikan perusahaan industri dan lain-lain. Hal ini disebabkan karena lebih mudahnya didapatkan izin dan terutama kredit bank.

c. Kelebihan modal di kota lebih banyak daripada di desa.

d. Pendidikan (terutama pendidikan lanjutan) lebih banyak di kota dan dengan sendirinya lebih mudah di dapat.

e. Kota merupakan suatu tempat yang lebih menguntungkan untuk mengembangkan jiwa dengan sebaik-baiknya dan seluas-luasnya.

f. Kota dianggap mempunyai tingkat kebudayaan yang lebih tinggi dan merupakan tempat pergaulan dengan segala macam orang dan dari segala lapisan.

\section{Penelitian Terdahulu}

Berdasarkan hasil penelitian yang telah dilakukan oleh beberapa orang mengenai faktor Beralihnya tenaga kerja ke sektor non-pertanian, maka hasil penelitian yang diperoleh antara lain sebagai berikut:

1. Pesik, dkk (2016), melakukan penelitian yang berjudul "Faktor-Faktor Penyebab Pergeseran Tenaga Kerja Sektor Pertanian Ke Sektor Non Pertanian Di Kecamatan Kalawat, Kabupaten Minahasa Utara", hasil penelitian yang diperoleh menunjukkan bahwa faktor pendorong utama yang menyebabkan tenaga kerja meninggalkan pekerjaan di sektor pertanian adalah pendapatan di sektor pertanian yang tidak menentu dan rendah serta ketersediaan lahan pertanian yang semakin berkurang. Faktor penarik utama dari sektor non-pertanian adalah semakin terbukanya peluang dan kesempatan kerja di sektor non-pertanian. Faktor penarik lainnya adalah pendapatan di sektor non-pertanian dan kondisi pekerjaan yang lebih menjanjikan.

Penelitian ini memiliki persamaan dengan penelitian yang sebelumnya yang dilakukan oleh Pesik, dkk (2016), dalam hal pendapatan di sektor pertanian yang tidak menentu dan rendah serta adanya alih fungsi lahan. Dan perbedaan penelitian ini dengan penelitian terdahulu Pesik (2016) adalah tempat penelitian yang berbeda.

2. Noragawati (2002), melakukan penelitian yang berjudul "Faktor Penyebab Pergeseran Tenaga Kerja Dari Sektor Pertanian Ke Sektor NonPertanian Pada Masyarakat Desa Telukpinang Kecamatan Ciawi Kabupaten Bogor", hasil penelitian menunjukkan bahwa:
(1) Berkembangnya industri di Desa Telukpinang menyebabkan beberapa dampak yaitu berupa terjadinya perubahan pola pemanfaatan lahan untuk kegiatan industri dan pemukiman.

(2) Perubahan jumlah penduduk yang diakibatkan oleh fertilitas dan migrasi.

(3) Kesempatan kerja atau lapangan pekerjaan yang tersedia yang kemudian memunculkan aktivitas perekonomian baru.

(4) Daya dorong dari pertanian yang meliputi tingkat upah yang rendah dan tidak teratur serta luas lahan pertanian yang semakin menyempit, sedangkan daya tarik dari sektor non-pertanian adalah tingkat upah lebih tinggi dan teratur, status sosial lebih tinggi serta suasana kerja yang nyaman dibanding bekerja di sektor pertanian.

(5) Umur tenaga kerja mempengaruhi pilihan pekerjaan setelah keluar dari sektor pertanian.

(6) Pendidikan mempengaruhi tenaga kerja untuk beralih dari sektor pertanian.

(7) Luas penguasaan lahan mempengaruhi pilihan tenaga kerja untuk melakukan pergeseran mata pencaharian

(8) Jenis kelamin tidak mempengaruhi dalam terjadinya pergeseran tenaga kerja dari sektor pertanian ke sektor non-pertanian, hal tersebut disebabkan oleh dominasi lakilaki disektor pertanian.

Penelitian ini memiliki persamaan dengan penelitian yang sebelumnya yang dilakukan oleh Norawati (2002). Dalam hasil penelitian tentang daya dorong dari sektor pertanian meliputi tingkat upah yang rendah, adanya alih fungsi lahan dan daya tarik dari sektor non-pertanian meliputi tingkat upah lebih tinggi dan teratur, status sosial lebih tinggi serta suasana kerja yang lebih nyaman dibandingkan bekerja di sektor pertanian. Dan perbedaan penelitian ini dengan penelitian terdahulu Noragawati (2002) adalah tempat penelitian yang berbeda.

\section{Rumusan Masalah}

Berdasarkan latar belakang yang telah diuraikan maka rumusan masalah dalam penelitian ini beralihnya anak petani bekerja disektor non-pertanian mengancam ketersedian komoditi pertanian nasional. Untuk itu perlu diketahui alasan mengapa anak petani tidak lagi tertarik untuk meneruskan profesi orangtuanya. 


\section{Tujuan Penelitian}

Tujuan dari penelitian ini adalah untuk mengetahui faktor-faktor apa saja yang menyebabkan beralihnya anak petani ke sektor non-pertanian di Desa Treman, Kecamatan Kauditan, Kabupaten Minahasa Utara.

\section{Manfaat Penelitian}

Penelitian ini diharapkan dapat menunjukkan bagi penulis adalah untuk meningkatkan pengetahuan tentang faktor-faktor yang menyebabkan beralihnya tenaga kerja dari sektor pertanian ke sektor non-pertanian. Dan juga dapat memberikan tambahan wawasan terhadap perubahan dalam strukur tenaga kerja.

\section{METODOLOGI PENELITIAN}

\section{Lokasi dan Waktu Penelitian}

Lokasi tempat penelitian dilakukan adalah di Desa Treman, Kecamatan Kauditan, Kabupaten Minahasa Utara. Penelitian dilakukan selama enam bulan yaitu dari bulan Januari sampai bulan Juni 2018.

\section{Metode Pengambilan Sampel}

Pengambilan sampel dalam penelitian ini adalah anak petani yang telah bekerja di sektor non-pertanian. Orang tua responden adalah petani pemilik lahan, petani pemilik lahan dan penggarap, serta petani penggarap. Pengambilan sampel dalam penelitian ini menggunakan metode pengambilan sampel secara sengaja (purposive sampling). Dalam penelitian ini responden adalah anak petani yang mewakili Jaga I-XVIII di Desa Treman, Kecamatan Kauditan, Kabupaten Minahasa Utara.

\section{Metode Pengumpulan Data}

Pengumpulan data yang digunakan dalam penelitian ini adalah data primer dan data sekunder. Data primer adalah data yang diperoleh secara langsung dari lapangan melalui wawancara, dan observasi non-partisipasi. Wawancara merupakan suatu proses penggalian data yang dilakukan oleh peneliti untuk mendapatkan informasi menyeluruh sesuai fakta yang ada berdasarkan daftar pertanyaan kepada tenaga kerja anak petani yang beralih pekerjaan ke sektor non-pertanian. Agar mendapat data tenaga kerja anak petani yang beralih pekerjaan ke sektor non-pertanian peneliti melakukan wawancara terlebih dahulu dengan Kepala Jaga I-XVIII (RT/RW) Desa Treman dan kepada responden, guna mendapatkan data sebelum penentuan responden. Data sekunder diperoleh melalui Kantor Desa Treman, Kecamatan Kauditan, Kabupaten Minahasa Utara.

\section{Data Primer yang Dikumpulkan}

Variabel-variabel yang dikaji dalam penelitian ini adalah

1. Karakteristik Responden

(1) Umur responden, yaitu dilihat dari umur anak petani yang dinyatakan dalam tahun.

(2) Jenis kelamin, yaitu laki-laki dan perempuan $(\mathrm{L} / \mathrm{P})$.

(3) Tingkat pendidikan, yaitu dilihat dari pendidikan terakhir yang di tempuh responden diukur dalam tahun.

(4) Jenis mata pencaharian, yaitu dilihat dari jenis pekerjaan yang dilakukan oleh responden.

(5) Status kepemilikan lahan dari orang tua responden.

2. Berdasarkan jawaban responden maka alasan responden akan dikelompokkan sesuai dengan pemikiran Soekanto, (2017) antara lain:

a. Faktor Pendorong

1) Alih fungsi lahan pertanian menjadi bangunan dan jalan.

2) Kurangnya pemahaman dan kemauan bekerja di sektor pertanian.

b. Faktor Penarik

1) Tingkat upah/gaji di sektor pertanian dan non-pertanian.

2) Pandangan anak petani terhadap pekerjaan di sektor pertanian dan nonpertanian.

3) Terbukanya peluang untuk bekerja di sektor non-pertanian.

\section{Analisis Data}

Analisis data dalam penelitian ini yaitu analisis deskriptif kualitatif dalam bentuk tabel. Dimana data primer yan diperoleh diolah dilakukan dengan proses mengatur, mengurutkan data yang terkumpul yang terdiri dari catatan lapangan, baik melalui wawancara, observasi, dan dokumentasi. Data tersebut diatur dan diurutkan, ditabulasi sesuai dengan kebutuhan peneliti, sehingga informasi 
kualitatif disusun atas pikiran, intuisi, pendapat, tentang faktor beralihnya tenaga kerja anak petani ke sektor non-pertanian di Desa Treman Kecamatan Kauditan Kabupaten Minahasa Utara. Dengan melakukan proses analisis data tersebut, maka data yang diperoleh akan memberi gambaran secara deskriptif.

\section{HASIL DAN PEMBAHASAN}

\section{Gambaran Umum Lokasi Penelitian}

\section{Sejarah Desa Treman}

Awal mulanya disekitar pertengahan tahun 1525 dari sekelompok masyarakat kecil dari Desa Walantakan sebutan waktu itu yang sekarang Tonsea Lama, pada waktu itu dibawah pimpinan Dotu Lengkong,Wulur dan Rensina bersama-sama dengan Tonaas Paruntu dan Makalew mereka bermufakat untuk mencari tempat baru untuk dijadikan pemukiman/ kampung sebagai tempat tinggal mereka dengan berkelana ke utara mengikuti kali Sawangen. Tempat pertama yang mereka temui dan tinggal menetap mereka namakan tempat itu "Kelewer" yg sekarang ini dikenal dengan sebutan Deposela, yang terletak 15 lintang utara dengan jarak kurang lebih $22 \mathrm{~km}$ dari Walantakan. Letaknya pada bagian selatan dengan pegunungan Dembean, yang pada bagian utara rawa yang dibatasi dengan sungai Samidow, tempat ini adalah sebagian rawa yang cocok untuk dijadikan daerah persawahan, sebab ditengahtengah rawa yang luas ini mangalir sungai Sawangen.

Setelah 7 tahun lamanya mereka tinggal menetap disitu dengan melalui ritual-ritual adat, mereka bermohon kepada Tuhan (Opo Empung) melalui kepercayaan waktu itu sebagai perantaraan burung Manguni (Doyot) bahwa tempat itu belum dapat dikabulkan sehingga pada tahun 1532 tempat itu mereka tinggalkan dan berpindah menuju utara dan sampailah mereka di suatu tempat yang mereka namakan tempat itu "Keraris" ditempat ini hal yang sama juga terjadi yaitu mereka tidak betah dan mereka berpindah lagi menuju arah timur sehingga sampai pada suatu tempat yang oleh mereka namakan "Tengat Watu" atau sekarang bernama perkebunan Eris dengan jarak 2,5 km dari Keraris. Tempat ini terdapat peninggalan sejarah yaitu lesung yang terbuat dari batu dalam bahasa daerah Tonsea disebut Tengat Watu. Pada tahun 1546 mereka (rombongan keluarga) berpindah lagi, karena selama itu tempat yang mereka diami menurut mereka belum direstui oleh Tuhan (Opo Empung) dikarenakan banyaknya gangguan berupa penyakit. Maka berjalanlah mereka menuju arah timur dan sampailah mereka disuatu tempat yang oleh mereka dinamakan "Tongkeina". Tongkeina ini letaknya memanjang dari sebelah utara ke selatan kira-kira $1,5 \mathrm{~km}$ dari Eris yang pada bagian selatan terdapat sungai Sawangen, pada bagian barat terdapat kali kecil yang mengalir di antara 2 tebing.

Kehidupan mereka disini agak berbeda dengan tempat yang terdahulu, sehingga sebagaimana tersebut di atas karena tempat ini oleh Dotu Lengkong, Rensina bersama-sama Tonaas Makalew dan sanak, keluarga berkembang menjadi banyak dan membentuk suatu kampung halaman mereka dengan menamakan tempat itu "Tareuman", Tareuman itu sendiri berasal dari ucapan Dotu Lengkong pada saat itu melalui ritual adat dengan perantaraan Burung Manguni (Doyot) mereka mendapat jawaban pasti bahwa tempat ini sudah Dikabulkan atau direstui oleh Tuhan (Opo Empung) yang dalam bahasa daerahnya yaitu: Tareuman Kinalelean $\mathrm{Ni}$ Opo Empung Um Pamikiwean yang resminya nama kampung tersebut yaitu Tareuman saat ini tempat tersebut disebut-sebut dengan nama Minawanua yang artinya bekas kampung atau desa. Tempat ini juga sampai sekarang banyak terdapat peninggalan sejarah sebagai bukti yaitu kuburan tua, warugawaruga yang diantaranya terdapat waruga dari Dotu Lengkong. Selain itu ada juga bekas benteng pertahanan yang mengelilingi tebing antara lain batu-batu besar serta rumpun bambu yang unik dan khas yaitu bambu tersebut mempunyai duriduri yang melingkar.

Selanjutnya selama 160 tahun mereka bermukim mereka bergeser lagi sedikit ke utara dan tempat itu mereka namakan "Tareuman Unet/Pinecisan" setelah mereka bermukim kurang lebih 40 tahun lamanya atau pada tahun 1801 mereka bergeser lagi sedikit kesebelah utara karena rombongan masyarakat ini sudah berkembang besar maka dari sebagian rombongan tinggal menetap di tempat ini dan mereka namakan tempat ini Tareuman Wangko dan saat ini sudah menjadi tempat tinggal abadi dan kekal sampai pada sekarang ini dengan nama "Treman" Berdasarkan penuturan dari orang-orang tua yaitu dotu-dotu dari masyarakat Tareuman dikatakan 
bahwa pemerintahan di kampung sudah dimulai sejak rombongan ini berada di Tongkeina yang pada waktu itu sudah dihulu balangi oleh Tonaas. Kemudian sudah terhitung mulai tahun 1685 s/d 1698 selama 13 tahun lamanya mereka sudah berpemerintahan (sudah ada yang mengatur) oleh mereka sendiri dipilih "Hukum Tua".

Urutan nama-nama Hukum Tua dari Tongkeina (Tareuman) sampai dengan sekarang dapat dilihat pada Tabel 1.

Berdasarkan sejarah yang pertama kalinya datang dan menetap di Treman adalah Suku Minahasa dengan 5 (Lima) orang Dotu $=$ Nenek moyang, yaitu: Pinontoan, Lengkong, Makalew, Paruntu, Rensina. Seiring dengan waktu yang terus berputar, maka dari sekelompok orang yang ada ini, kemudian terus bertambah banyak, dengan, masuknya beberapa suku diantaranya suku Sangihe-Talaud, Bolaang Mongondow, dan Ternate. yang akhirnya kawin-mawin dan beranak cucu. Dan nama "Tiwow" menjadi nama kampung dan akhirnya berubah menjadi sebutan "Desa Treman".

Tabel 1. Daftar nama-nama Hukmm Tua Desa Treman

\begin{tabular}{|c|c|c|c|}
\hline No & Nama & Masa Jabatan & Tempat/lokasi \\
\hline 1. & Lentrong & $1698 \mathrm{~s} / \mathrm{d} 1718(20 \mathrm{Th})$ & Tong giverina \\
\hline 2. & Sumampouw & $1719 \mathrm{~s} / \mathrm{d} 1735(16 \mathrm{Thn})$ & Tareuman \\
\hline 3. & Weenas & $1735 \mathrm{~s} / \mathrm{d} 1759(24 \mathrm{Thn})$ & Tareuman \\
\hline 4. & Dendeng & $1759 \mathrm{~s} / \mathrm{d} 1760(1 \mathrm{Thn})$ & Tareuman \\
\hline 5. & Umboh & $1760 \mathrm{~s} / \mathrm{d} 1776(16 \mathrm{Thn})$ & Tareuman Unet/Pinecisan \\
\hline 6. & Lontoh & $1776 \mathrm{~s} / \mathrm{d} 1786(10 \mathrm{Thn})$ & Tareuman Unet/Pinecisan \\
\hline 7. & Worotikan & $1786 \mathrm{~s} / \mathrm{d} 1787(1 \mathrm{Thn})$ & Tareuman Unet/Pinecisan \\
\hline 8. & Nelwan Tasiam & $1787 \mathrm{~s} / \mathrm{d} 1801(14 \mathrm{Thn})$ & Tareuman Unet/Pinecisan \\
\hline 9. & Judis Nelwan & $1801 \mathrm{~s} / \mathrm{d} 1825(25 \mathrm{Thn})$ & Tareuman Wangko (Treman) \\
\hline \multirow[t]{2}{*}{10.} & Katuut Kawii & $1825 \mathrm{~s} / \mathrm{d} 1837(12 \mathrm{Thn})$ & Tareuman Wangioo (Treman) \\
\hline & Catatar: $\begin{array}{c}\text { Huimm Tua i } \\
(\text { (kidaij/kanii }\end{array}$ & dajam m & \\
\hline 11. & Nentur & $1837 \mathrm{~s} / \mathrm{d} 1854(17 \mathrm{Th})$ & Tareuman Wangko (Treman) \\
\hline 12. & Nalo Warouw & $1854 \mathrm{~s} / \mathrm{d} 1860(6 \mathrm{Thn})$ & Tareuman Wangko (Treman) \\
\hline 13. & Kerestian Damopolii & $1860 \mathrm{~s} / \mathrm{d} 1862(2 \mathrm{Thn})$ & Tareuman Wanglo (Treman) \\
\hline 14. & Jonathan Direk & $1862 \mathrm{~s} / \mathrm{d} 1863(1 \mathrm{Th})$ & Tareuman Wangko (Treman) \\
\hline 15. & Komeles Lengkong & $1863 \mathrm{~s} / / \mathrm{d} 1870(7 \mathrm{Th})$ & Tareuman Wanglo (Treman) \\
\hline \multirow[t]{2}{*}{16.} & Petrus Tuwaidan & $1870 \mathrm{~s} / \mathrm{d} 1910(40 \mathrm{Thn})$ & Tareuman Wangko (Treman) \\
\hline & $\begin{array}{c}\text { Catatar: Huimm Tua yam } \\
\text { tugasmya. }\end{array}$ & gernañ diamugrài/mendar & t bintang tanda jasa karena ma \\
\hline 17. & Eduard Lengrong & $1910 \mathrm{~s} / \mathrm{d} 1917(7 \mathrm{Thn})$ & Tareuman Wangko (Treman) \\
\hline 18. & Sumampouw (Thomas) & $1917 \mathrm{~s} / \mathrm{d} 1919(2 \mathrm{Thn})$ & Tareuman Wangko (Treman) \\
\hline \multirow[t]{2}{*}{19.} & Johanis Katuuk & $1919 \mathrm{~s} / \mathrm{d} 1921$ (2 Thn $)$ & Tareuman Wangko (Treman) \\
\hline & $\begin{array}{l}\text { Catatar: Hukim Tua san } \\
\text { Kawiliey dan } K=\end{array}$ & $\begin{array}{l}\text { bung yang kepemimpinan } \\
\text { ditan }\end{array}$ & a mencakup 3 desa Yaini, Tremc \\
\hline 20. & Joost Worotilan & $1921 \mathrm{~s} / \mathrm{d} 1937(16 \mathrm{Thn})$ & Tareuman Wangko (Treman) \\
\hline 21. & Albert Tuwaidan & $1937 \mathrm{~s} / \mathrm{d} 1950(13 \mathrm{Thn})$ & Tareuman Wanglo (Treman) \\
\hline 22. & Geradus Lengkong & $1950 \mathrm{~s} / \mathrm{d} 1957(13 \mathrm{Thn})$ & Tareuman Wanglo (Treman) \\
\hline 23. & Albert Tasiam & 1957 s/d 1958 (1 Thn) & Tareuman Wangko (Treman) \\
\hline 24. & Apeles Waturandang & $1958 \mathrm{~s} / \mathrm{d} 1962(4 \mathrm{Thn})$ & Tareuman Wangko (Treman) \\
\hline 25. & George Lenglong & $1962 \mathrm{~s} / \mathrm{d} 1965(3 \mathrm{Thn})$ & Tareuman Wangko (Treman) \\
\hline 26. & Jhon Pangamanan & $1965 \mathrm{~s} / \mathrm{d} 1974(9 \mathrm{Thn})$ & Tareuman Wangko (Treman) \\
\hline 27. & Petrus T. Waturandang & $1974 \mathrm{~s} / \mathrm{d} 1977(3 \mathrm{Thn})$ & Tareuman Wangho (Treman) \\
\hline 28. & Nikodernus Tuwaidan & $1977 \mathrm{~s} / \mathrm{d} 1987(10 \mathrm{Thn})$ & Tareuman Wangko (Treman) \\
\hline 29. & Karel P. Lenglon & $1987 \mathrm{~s} / \mathrm{d} 1988(1 \mathrm{Th})$ & Tareuman Wangko (Treman) \\
\hline 30. & Bernadus B. Melekel & $1988 \mathrm{~s} / \mathrm{d} 1999(10 \mathrm{Thn})$ & Tareuman Wangko (Treman) \\
\hline 31. & Estefien T. Tuwaidan & $1999 \mathrm{~s} / \mathrm{d} 2007(7 \mathrm{Thn})$ & Tareuman Wanglo (Treman) \\
\hline 32. & Bemhard W. J. Tuwaidan & $2007 \mathrm{~s} / \mathrm{d} 2013(6 \mathrm{Thn})$ & Tareuman Wangko (Treman) \\
\hline 33. & Silvia G. A. Moningta & $2014 \mathrm{~s} / \mathrm{d} 2015(1 \mathrm{Thn})$ & Tareuman Wangko (Treman) \\
\hline 34. & Fenny J. Katunk, SPi & 2015 s/d 2015 (Plt) & Tareuman Wangko (Treman) \\
\hline 35. & Bernadus B. Dumanauw & 2016 - Selarang & Tareuman Wangho (Treman) \\
\hline
\end{tabular}

\section{Kondisi Umum Desa Treman}

Desa Treman merupakan salah satu desa yang terletak di ujung Barat dari Kabupaten Minahasa Utara, dan salah satu dari 19 desa di Wilayah Kecamatan Kauditan, Propinsi Sulawasi Utara. Desa Treman berjarak $3 \mathrm{~km}$ arah Utara dari Ibukota Kecamatan di Airmadidi dan berjarak $\pm 30 \mathrm{~km}$ dari Ibukota Kabupaten Minahasa Utara di Airmadidi, dan berjarak $\pm 20 \mathrm{~km}$ dari Ibukota Propinsi Sulawesi Utara di Kota Manado.

Desa Treman mempunyai luas wilayah mencapai 557,295 ha dengan jumlah jaga yaitu 18 wilayah Jaga. Desa Treman berbatasan dengan:

a. Sebelah Utara berbatasan dengan Gunung Klabat.

b. Sebelah Timur berbatasan dengan Desa Kawiley Kecamatan Kauditan dan Desa Lansot Kecamatan Kema.

c. Sebelah Selatan berbatasan dengan Desa Lilang Kecamatan Kema.

d. Sebelah Barat berbatasan dengan Desa Kaima Kecamatan Kauditan.

Wilayah Desa Treman menurut penggunaan lahan pertanian sesuai dengan data yang diperoleh dari Kantor Desa Treman (2017) yaitu seluas 894 ha.

\section{Karakteristik Responden}

\section{Jumlah Responden Menurut Kelompok Umur}

Umur tenaga kerja anak petani yang beralih pekerjaan ke non-pertanian mempengaruhi produktivitas kerja atau perannya dalam pengambilan keputusan dan kemampuan dalam bekerja di berbagai pekerjaan yang dilakukan. responden yang telah beralih pekerjaan ke sektor non-pertanian, yang termuda berumur 18 tahun sedangkan yang tertua adalah 31 tahun. Adapun kelompok umur dibagi menjadi empat kelompok umur yaitu $\leq 20$ tahun, $21-25$ tahun, $26-30$, > 30. Jika dilihat dari segi fisik, secara umum tenaga kerja anak petani cenderung memiliki kemampuan yang jauh lebih baik pada saat melakukan berbagai pekerjaan. Tabel 2 menunjukkan jumlah responden menurut kelompok umur.

Tabel 2. Jumlah Responden Menurut Kelompok Umur

\begin{tabular}{llcr}
\hline No & Umur (Tahun) Jumlah (Orang) & Persentase (\%) \\
\hline 1. & $\leq 20$ & 5 & 27,78 \\
2. & $21-30$ & 12 & 66,67 \\
3. & $>30$ & 1 & 5,56 \\
\hline & Jumlah & 18 & 100 \\
\hline
\end{tabular}

Sumber: Diolah dari Data Primer, 2018 
Tabel 2 menunjukkan bahwa kebanyakan responden yang berada pada kisaran umur antara 21-30 tahun. Umur anak petani yang menjadi responden rata-rata masuk dalam kriteria tenaga kerja produktif.

\section{Jumlah Responden Menurut Jenis Kelamin}

Jenis kelamin atau gender merupakan sesuatu yang membedakan antara laki-laki dan perempuan sesuai dengan kedudukannya. Tabel 3 menjelaskan mengenai tenaga kerja anak petani yang beralih pekerjaan ke sektor non-pertanian berdasarkan jenis kelamin.

Tabel 3 menunjukkan jenis kelamin responden laki-laki dan perempuan sama banyak dengan persentase $50,00 \%$.

Tabel 3. Jenis Kelamin Responden

\begin{tabular}{llcr}
\hline No & Jenis Kelamin & Jumlah (Orang) & Persentase (\%) \\
\hline 1. & Laki-laki & 9 & 50,00 \\
2. & Perempuan & 9 & 50,00 \\
\hline & Jumlah & 18 & 100 \\
\hline
\end{tabular}

Sumber: Diolah dari Data Primer, 2018

\section{Jumlah Responden Menurut Tingkat Pendidikan}

Pendidikan diperoleh setiap orang dengan dua cara yaitu secara formal dan non-formal. Pendidikan sangat penting dalam usaha peningkatan kualitas sumber daya manusia, dimana tenaga kerja anak petani juga termasuk dalam sumber daya manusia untuk membangun tenaga kerja yang berkompetensi dan unggul di bidang tertentu, serta meningkatkan mutu intelektual dan wawasan seseorang. Tabel 4 menjelaskan mengenai tenaga kerja anak petani yang beralih pekerjaan ke sektor non-pertanian berdasarkan tingkat pendidikan.

Tabel 4. Jumlah Responden Menurut Tingkat Pendidikan

\begin{tabular}{lll}
\hline No. Tingkat Pendidikan & Jumlah (Orang) & Persentase (\%) \\
\hline
\end{tabular}

\begin{tabular}{clcr} 
1. & SD (tamat) & 1 & 5,56 \\
2. & SMA/SMK (Tamat) & 10 & 55,56 \\
3. & Diploma/S1 & 7 & 38,89 \\
\hline & Jumlah & 18 & 100,00 \\
\hline
\end{tabular}

Sumber: Diolah dari Data Primer, 2018

Tabel 4 menunjukkan tingkat pendidi-kan anak petani khususnya penduduk usia produktif. Jumlah anak petani yang berhasil menamatkan Sekolah Dasar dengan angka persentase sebesar $5,56 \%$ dengan jumlah responden sebanyak 1 orang, sedangkan penduduk yang berhasil menamatkan SMA/SMK sebesar 55,56\% dengan jumlah responden sebanyak 10 orang, yang merupakan persentase terbesar. Kemudian diikuti responden yang berhasil menamatkan pendidikannya di perguruan tinggi yaitu sebesar $38,89 \%$ dengan jumlah responden sebanyak 7 orang.

\section{Jumlah Responden Menurut Jenis Mata Pencaharian}

Pekerjaan merupakan kegiatan yang dapat menghasilkan bagi setiap orang. Karena dengan melakukan pekerjaan atau mendapatkan pekerjaan dapat menghasilkan uang sebagai balas jasa terhadap pekerjaan yang telah dikerjakan. Jenisjenis mata pencaharian yang di kerjakan oleh anak petani (Responden) di Desa Treman, dapat dilihat pada Tabel 5.

Tabel 5. Jenis Mata Pencaharian Responden

\begin{tabular}{llcr}
\hline No & \multicolumn{1}{c}{$\begin{array}{c}\text { Jenis Mata Pencaharian } \\
\text { Responden }\end{array}$} & $\begin{array}{c}\text { Jumlah } \\
\text { (Orang) }\end{array}$ & Persentase (\%) \\
\hline 1. & Honorer (Guru, Pegawai & 2 & 11,11 \\
& Pemkab Minut) & & 5,56 \\
2. & Asuransi Wahana Tata & 1 & 11,11 \\
3. $\quad$ Pegawai Bank & 2 & 5,56 \\
4. $\quad$ Pranata Laboratorium RSUP & 1 & 22,22 \\
& Prof. Kandou & & 16,67 \\
5. $\quad$ Perusahaan Terbatas (PT) & 4 & 11,11 \\
6. $\quad$ Mini Market & 3 & 11,11 \\
7. & Wiraswasta & 2 & 5,56 \\
8. $\quad$ Security & 2 & 100,00 \\
9. & Pekerja Jalan Tol & 1 & \\
\hline & Jumlah & 18 &
\end{tabular}

Tabel 5 menunjukkan bahwa terdapat 9 jenis mata pencaharian anak petani yang menjadi responden. Jenis mata pencaharian yang paling banyak diminati adalah pada jenis mata pencaharian di perusahaan terbatas dengan jumlah responden 4 orang dengan persentase $22,22 \%$. Kemudian diikuti jenis mata pencaharian pada mini market dengan jumlah responden 3 orang dengan persentase $16,67 \%$.

\section{Penguasaan Lahan dan Status Petani (Orang tua)}

Lahan merupakan faktor produksi yang sangat menentukan bagi proses pembangunan ekonomi suatu negara. Negara yang memiliki lahan yang subur sangatlah mungkin memiliki tingkat produktivitas pertanian yang tinggi pada tahap awal dari pertumbuhan ekonomi. Peningkatan produktivitas pertanian akan sangat mempengaruhi perkembangan sektor-sektor lain seperti sektor industri dan jasa pada tahap perkembangan ekonomi lebih lanjut (Suparmoko, 2008). 
Status penguasaan lahan pertanian yang di miliki oleh orang tua responden, dapat dilihat pada Tabel 6.

Tabel 6. Penguasaaan Lahan dan Status Petani dari Orang tua Responden

\begin{tabular}{lc}
\multicolumn{1}{c}{ Responden } & Jumlah \\
\hline Status Petani (Orang tua) & \\
\hline Milik Sendiri: & 3 \\
- Pemilik & 8 \\
- Pemilik/Penggarap & \\
\hline Bukan milik sendiri: & 3 \\
- Penggarap lahan milik keluarga besar & 4 \\
- Penggarap milik orang lain & 18 \\
\hline Jumlah &
\end{tabular}

Tabel 6 menunjukkan penguasaan lahan dan status petani (orang tua responden) dari 18 responden, yang terdiri dari milik sendiri sebanyak 3 orang sebagai pemilik lahan tetapi tidak menggarap, 8 orang sebagai pemilik/ penggarap yang menjadi pemilik sekaligus yang menggarap lahan. Sedangkan yang bukan milik sendiri terdapat 3 orang sebagai penggarap lahan milik keluarga besar, dan 4 orang sebagai penggarap lahan milik orang lain dengan cara antara lain bagi hasil.

\section{Faktor Penyebab Beralihnya Tenaga Kerja Anak Petani ke Sektor Non-Pertanian}

Faktor penentu beralihnya tenaga kerja anak petani ke sektor non-pertanian dapat dikelompokkan dalam dua kelompok besar, sesuai dengan pemikiran Soekanto (2017), yaitu faktor pendorong dan faktor penarik.

\section{Faktor Pendorong}

Faktor pendorong, yang ditemukan dalam penelitian ini adalah (1) Alih Fungsi Lahan Milik Orang Tua Responden Menjadi Bangunan dan Jalan, dan (2) Kurangnya Pemahaman dan Kemauan Bekerja di Sektor Pertanian.

\section{Alih Fungsi Lahan Milik Orang Tua Responden Menjadi Bangunan dan Jalan}

Lahan merupakan modal dasar dalam kegiatan dibidang pertanian. Fungsi lahan bagi masyarakat Desa Treman salah satunya sebagai modal dalam usahatani. Luas wilayah Desa Treman adalah 557,295 ha, dengan jumlah luas lahan pertanian yaitu seluas 894 ha. Luas kepemilikan lahan yang dimanfaatkan oleh orang tua responden untuk sektor pertanian bervariasi, antara lain tanaman pangan seperti padi, tanaman tahunan seperti kelapa dan cengkeh, tanaman hortikultura cabe, tomat, kacang panjang, dan terong, tanaman buah-buahan seperti pisang, jagung, dan kacang tanah. Persentase kepemilikan lahan dari responden di Desa Treman dapat dilihat pada Tabel 7.

\begin{tabular}{lcr}
\multicolumn{3}{l}{ Tabel 7. Luas Kepemilikan Lahan Orang Tua Responden } \\
\hline Luas Lahan (Ha) & Jumlah (Orang) & Persentase (\%) \\
\hline$<0,50$ & 3 & 16,67 \\
$0,50-1,00$ & 5 & 27,78 \\
$>1,00$ & 10 & 55,56 \\
\hline Total & 18 & 100,00 \\
\hline Sumber: Diolah dari Data Primer, 2018 &
\end{tabular}

Tabel 7 menunjukkan kepemilikan lahan dari orang tua responden. Jumlah kepemilikan lahan terbanyak yaitu pada luas lahan lebih dari sama dengan 0,1 ha dengan jumlah pemilik 10 orang pada jumlah persentase $55,56 \%$. Di ikuti dengan jumlah luas lahan sebesar 0,50-1,00 ha dengan jumlah pemilik 5 orang pada jumlah persentase $27,78 \%$. Kemudian jumlah kepemili-kan luas lahan kurang dari 0,50 ha dengan jumlah pemilik 3 orang pada jumlah persentase $16,67 \%$.

\section{Kurangnya Pemahaman dan Kemauan Bekerja di Sektor Pertanian}

Kemauan dalam melakukan pekerjaan adalah faktor dari dalam diri seseorang yang memberikan pilihan kepada orang tersebut, apakah dia mau atau tidak untuk melakukan pekerjaan yang bermanfaat bagi dirinya.

Berdasarkan hasil penelitian terhadap anak petani yang berada di Desa Treman, rata-rata anak petani yang menjadi responden menjawab bahwa mereka merasa kurang memahami bahkan ada yang tidak paham mengenai pertanian.

Kurangnya pemahaman dan kemauan dari anak petani yang memacu atau membuat sehingga anak petani tidak suka bekerja di sektor pertanian melainkan mereka lebih memilih untuk beralih pekerjaan dari sektor pertanian ke sektor nonpertanian. Tabel 8 menjelaskan alasan responden tentang kurangnya pemahaman bekerja di sektor pertanian.

Tabel 8. Alasan Tenaga Kerja Anak Petani di Desa Treman Beralih

\begin{tabular}{|c|c|c|c|}
\hline No & Alasan Responden & Jumlah (Orang) & Persentase (\%) \\
\hline 1) & $\begin{array}{l}\text { Tidak memiliki pengetahuan } \\
\text { yang cukup di sektor pertanian }\end{array}$ & 8 & 44,44 \\
\hline 2) & $\begin{array}{l}\text { Tidak ada kemauan untuk bekerja } \\
\text { di sektor pertanian }\end{array}$ & 8 & 44,44 \\
\hline 3) & $\begin{array}{l}\text { Bekerja di sektor pertanian } \\
\text { butuh kesabaran }\end{array}$ & 2 & 11,11 \\
\hline & Jumlah & 18 & 100,00 \\
\hline
\end{tabular}

Tabel 8 menunjukkan alasan responden tentang kurangnya pemahaman dan kemauan untuk bekerja di sektor pertanian, sehingga responden lebih memilih beralih pekerjaan ke sektor nonpertanian. Tidak memiliki pengetahuan yang cukup di sektor pertanian dan tidak ada kemauan untuk bekerja di sektor pertanian adalah yang sama banyaknya yang diungkapkan oleh responden yang berjumlah 8 orang dengan persentase $44,44 \%$. 
Alasan yang lain yang di ungkapkan oleh responden adalah tidak ada kemauan untuk bekerja di sektor pertanian dapat di jelaskan sebagai berikut:

1) Bekerja sesuai pada bidang ilmu yang telah ditempuh oleh responden selama pendidikan terakhir.

Sebagaimana yang di ungkapkan oleh salah satu responden KR (28 Tahun) yang bekerja di PT. Freeport Indonesia, berikut ini:

"kita nyanda ba kerja di pertanian karna bukang kita pe bidang ilmu waktu kita ada selesai kuliah, kong lhey qt nyanda talalu mangarti cara ba tani. Jadi, kita lebe pilih ba kerja di luar pertanian".

("Saya tidak bekerja di bidang pertanian karena bukan merupakan bidang ilmu yang saya terima sewaktu saya kuliah, dan saya juga tidak mengerti bagaimana cara bertani. kemudian saya lebih memilih untuk bekerja pada sektor non-pertanian").

2) Lebih dihargai bekerja pada sektor nonpertanian dan menaikkan status sosial.

Sebagaimana yang di ungkapkan oleh salah satu responden ASK (28 Tahun) yang bekerja sebagai Staff pada Assuransi Wahana Tata berikut ini:

"kalau menurut kita, ba kerja di luar sektor pertanian lebih di hargai, mar itu pendapat orang laeng yang biasa ba karlota. mar kalo dari kita sediri, tergantung dari diri sendiri bagimana mo jalani tu kerja nda pusing orang pe mulu-mulu kerlota yang penting kerja yang bae-bae dan halal".

("Kalau menurut saya, bekerja di luar pertanian lebih dihargai, tetapi hal itu merupakan tanggapan dari ibu-ibu tetangga yang biasanya mulai kumpul untuk ngerumpi. Tapi kalau menurut saya sendiri, hal itu tergantung pada bagaimana cara saya menjalani pekerjaan saya, tanpa memusingkan komentar orang lain yang terpenting pekerjaan tersebut merupakan pekerjaan yang baik dan halal").

3) Ingin meningkatkan pengalaman bekerja di sektor non-pertanian

Sebagaimana yang di ungkapkan oleh salah satu responden GCA (20 Tahun) yang bekerja sebagai karyawan swata di Alfamart, berikut ini:

"kita pilih ba kerja di luar pertanian karna mo cari pengalaman ba kerja di luar pertanian, deng kwa kita nintau ba kabong yang bae".

("Saya memilih untuk bekerja di luar pertanian karena ingin meningkatkan pengalaman bekerja diluar sektor pertanian, dan saya juga tidak mengetahui cara bertani yang baik").

4) Kondisi pekerjaan yang lebih baik dibandingkan kondisi pekerjaan di bidang pertanian

Sebagaimana yang di ungkapkan oleh salah satu responden IESL (18 Tahun) yang bekerja sebagai karyawan swata di Alfamart, berikut ini:

"Lebe enak ba kerja di luar pertanian karna nda mo kaluar suar banya, kuli nda mo angus karna matahari, depe suasana lebe enak dan nyaman karna ada AC, deng nyanda mo kena akang nyamu. Kalo ba kerja di kabong ta suar-suar deng pas baku mengada deng matahari pe panas kalo di musim panas, kalau di musim ujang basah kena akang ujang tambah lhey nyamu jaga gigi",.

("Lebih menyenangkan saat bekerja di luar sektor pertanian karena tidak mengeluarkan keringat berlebihan, kulit tidak akan hangus karena tidak terpapar dengan sinar matahari secara langsung, dan suasana saat bekerja jadi lebih menyenangkan dan nyaman karena difasilitasi dangan AC serta terbebas dari gigitan nyamuk. Dibandingkan kalau bekerja dikebun yang menguras banyak tenaga dan keringat serta berhadapan langsung dengan teriknya panas matahari pada saat musim kemarau dan kehujanan ketika musim hujan tiba ditambah pula dengan gigitan nyamuk").

\section{Faktor Penarik}

Faktor penarik, yang ditemukan dalam penelitian ini, adalah (1) Tingkat Upah/Gaji di Sektor Pertanian dan Non-Pertanian, (2) Pandangan Anak Petani Terhadap Pekerjaan di Sektor Pertanian dan Non-Pertanian, dan (3) Terbukanya Peluang untuk Bekerja di Sektor Non-Pertanian.

\section{Tingkat Upah/Gaji di Sektor Pertanian dan Non-Pertanian}

Upah/gaji merupakan penghasilan yang diterima oleh seseorang yang bekerja sebagai buruh, karyawan, pegawai pada instansi pemerintahan, kantor dan perusahaan untuk digunakan dalam memenuhi segala kebutuhan hidup baik secara pribadi dan keluarganya.

Hasil penelitian terhadap tingkat upah/gaji tenaga kerja anak petani yang beralih pekerjaan ke sektor non-pertanian di Desa Treman, Kecamatan Kauditan, Kabupaten Minahasa Utara, dari 18 orang responden. Dapat dilihat pada Tabel 9, dan Tabel 10. 
Tabel 9. Alasan Responden dilihat dari Besarnya Upah/gaji di Sektor Pertanian

\begin{tabular}{llcr}
\hline No & Alasan Responden & Jumlah (orang) & Persentase (\%) \\
\hline 1. & $\begin{array}{l}\text { Upah ditentukan oleh } \\
\text { hasil panen }\end{array}$ & 8 & 44,44 \\
2. & $\begin{array}{l}\text { Upah ditentukan } \\
\text { oleh harga jual }\end{array}$ & 10 & 55,56 \\
\hline & Jumlah & 18 & 100,00 \\
\hline Sumber: Diolah dari Data Primer, 2018
\end{tabular}

Sumber: Diolah dari Data Primer, 2018

Tabel 9 menunjukkan dua jawaban yang dikemukakan oleh masing-masing responden, yang berjumlah 18 orang tentang alasan responden dilihat dari upah/gaji di sektor pertanian. Upah di sektor pertanian ditentukan oleh hasil panen, menunjukkan bahwa responden yang beralih pekerjaan sebanyak 8 dari 18 responden $(44,44 \%)$. Hasil pertanian yang diusahakan antara lain tanaman cengkeh, pala, kelapa, padi, sayuran dan buah-buahan. Kemudian diikuti jawaban yang dikemukakan oleh responden tentang upah ditentukan oleh harga jual, yang terdiri dari 10 orang dengan persentase 55,56\%. Upah di sektor pertanian tidak menentu dan memerlukan waktuwaktu tertentu untuk dapat memperoleh upah.

Tabel 10. Alasan Responden dilihat dari Upah/gaji di Sektor Non- Pertanian

\begin{tabular}{llcc}
\hline No & $\begin{array}{l}\text { Alasan } \\
\text { Responden }\end{array}$ & Jumlah (Orang) & Persentase (\%) \\
\hline 1. & $\begin{array}{l}\text { Upah yang di } \\
\text { terima lebih pasti } \\
\text { perbulan, lebih } \\
\text { besar }\end{array}$ & 14 & 77,78 \\
\hline 2. & $\begin{array}{l}\text { Dapat insentif/ } \\
\text { Bonus tambahan } \\
\text { diluar gaji pokok } \\
\text { perbulan }\end{array}$ & 4 & 22,22 \\
\hline & & \\
\hline Jumlah & 18 & 100,00 \\
\hline Sumber: Diolah dari Data Primer, 2018
\end{tabular}

Sumber: Diolah dari Data Primer, 2018

Tabel 10 terdapat dua jawaban yang dikemukakan oleh masing-masing responden, yang berjumlah 18 orang tentang alasan responden dilihat dari upah/gaji di sektor nonpertanian. Jumlah responden yang menjawab upah/gaji yang diterima lebih pasti didapat, dan lebih besar berjumlah 14 orang dengan persentase $77,78 \%$. Kemudian diikuti pada jawaban responden tentang upah/gaji disektor nonpertanian mendapatkan insentif/bonus tambahan diluar gaji pokok perbulan berjumlah 4 orang dengan persentase $22,22 \%$. Upah di sektor nonpertanian merupakan upah yang sudah pasti akan diterima setiap bulan dan juga lebih menjanjikan bagi para pekerja yang bekerja di sektor ini dibandingkan dengan bekerja di sektor pertanian.

\section{Pandangan Anak Petani Terhadap Pekerjaan di Sektor Pertanian dan Non-Pertanian}

Pandangan merupakan cara seseorang melihat dan mendengar, serta menilai suatu kejadian, yang ada di lingkungan sekitarnya baik secara langsung maupun tidak langsung dengan tanggapan yang beragam, baik secara positif maupun secara negatif. Salah satu pembahasan dalam penelitian ini adalah tentang pandangan anak petani terhadap pekerjaan anak petani di sektor pertanian dan non-pertanian, dan bagaimana sikap dari anak petani menerima, pandangan orang lain baik secara positif dan negatif terhadap pekerjaan yang sedang dikerjakan di sektor non-pertanian.

Berikut ini adalah pandangan anak petani tentang pekerjaan di sektor pertanian dan nonpertanian, yaitu:

1) Pekerjaan di sektor pertanian di pandang rendah dan tidak menaikkan status sosial.

2) Pekerjaan di sektor pertanian merupakan pekerjaan kampungan.

3) Pekerjaan di sektor non-pertanian lebih menaikkan status sosial.

4) Pendapatan pada sektor pertanian membutuhkan waktu yang cukup lama.

5) Tingkat pendidikan yang relatif tinggi bekerja pada sektor pertanian tidaklah pantas buat mereka karena tidak sesuai dengan pendidikan yang selama ini mereka dapatkan.

\section{Terbukanya Peluang untuk Bekerja di Sektor Non-Pertanian}

Perkembangan modernisasi dan ekonomi asean pada saat ini membuka banyak peluang pekerjaan di luar sektor Pertanian. Banyak perusahaan di sektor non-pertanian yang memberikan atau membuka lapangan pekerjaan serta menerima tenaga kerja dengan gaji yang lebih besar dan menjanjikan. Dengan beberapa contoh persyaratan kerja yang harus di penuhi antara lain pendidikan (Min DIII/S1), umur (18 $\mathrm{T}-25$ tahun/sesuai dengan persyaratan yang di ajukan oleh beberapa pihak baik di bidang industri maupun di bidang jasa), tenaga (tubuh yang sehat jasmani dan rohani), keterampilan (memiliki kemampuan mengoperasikan komputer dan menguasai bahasa inggris), berkepribadian baik dan mudah bekerja sama dengan rekan kerja, bisa berbicara yang baik dan lancar, siap di tempatkan dimana pada daerah lain yang berada jauh dari tempat tinggal. 
Seiring perkembangan zaman yang semakin modern pada saat ini, tenaga kerja yang bekerja di sektor pertanian mengalami penurunan di karenakan adanya dorongan terhadap pemenuhan kebutuhan hidup, agar dapat mencukupi kebutuhan hidup. Karena pekerjaan di sektor pertanian tidak lagi menjanjikan. Tabel 11 menjelaskan alasan responden memiliih bekerja di sektor nonpertanian dilihat dari terbukanya peluang bekerja di sektor non-petanian.

\begin{tabular}{|c|c|c|c|}
\hline & $\begin{array}{l}\text { Non-Pertanian } \\
\text { Peluang Beker }\end{array}$ & $\begin{array}{c}\text { dilihat dari } \\
\text { di Sektor Non-F }\end{array}$ & $\begin{array}{l}\text { Terbukanya } \\
\text { Petanian }\end{array}$ \\
\hline No & Alasan & Jumlah (Orang) & Persentase (\%) \\
\hline 1. & $\begin{array}{l}\text { Terbukanya peluang } \\
\text { bekerja di sektor } \\
\text { non-pertanian }\end{array}$ & 12 & 66,67 \\
\hline 2. & $\begin{array}{l}\text { Kondisi pekerjaan } \\
\text { yang nyaman }\end{array}$ & 6 & 33,33 \\
\hline & Jumlah & 18 & 100,00 \\
\hline
\end{tabular}

Sumber: Diolah dari Data Primer, 2018

Tabel 11 menunjukkan alasan respon-den memilih bekerja di sektor non-pertanian dilihat dari terbukanya peluang bekerja di sektor nonpertanian. Terdapat dua tangapan yang dikemukakkan oleh responden antara lain yang pertama terbukanya peluang bekerja disektor non-pertanian sebanyak $66,67 \%$, dengan jumlah responden 12 orang, dikarena-kan banyak terbukanya peluang bekerja di sektor nonpertanian dibandingkan saat bekerja di sektor pertanian. Tanggapan yang kedua tentang kondisi pekerjaan yang nyaman sebanyak $33,33 \%$ dengan jumlah responden 6 orang dikarenakan saat bekerja disektor non-pertanian kondisi pekerjaan lebih nyaman.

\section{KESIMPULAN DAN SARAN}

\section{Kesimpulan}

Hasil penelitian yang dilakukan di Desa Treman menunjukkan bahwa terdapat 2 faktor beralihnya tenaga kerja anak petani ke sektor nonpertanian yaitu:

1. Faktor Pendorong

1) Alih fungsi lahan pertanian ke nonpertanian seperti berdirinya bangunan yang membuat lahan pertanian di gusur dan dijadikan bangunan dan jalan.
2) Kurangnya pemahaman dan kemauan bekerja di sektor pertanian. alasan responden tidak memiliki pengetahuan yang cukup di sektor pertanian dengan persentase $50,00 \%$ dikarenakan kurangnya informasi pengetahuan di sektor pertanian yang dimiliki oleh responden.

2. Faktor Penarik

1) Tingkat upah/gaji di sektor pertanian dan non-pertanian. Tingkat upah/gaji disektor pertanian menunjukkan upah/gaji ditentukan oleh harga jual hasil pertanian dengan persentase $55,56 \%$. Tingkat upah disektor non-pertanian menunjukkan upah/gaji yang diterima lebih cepat didapat dan lebih besar dengan persentase $77,78 \%$.

2) Pandangan anak petani terhadap pekerjaan disektor pertanian dan nonpertanian. Terdapat 4 pandangan yang dikemukakan oleh responden yaitu:

a. Bekerja sesuai bidang ilmu yang telah ditempuh oleh responden selama pendidikan terakhir.

b. Lebih dihargai bekerja pada sektor nonpertanian dan menaikkan status sosial.

c. Ingin meningkatkan pengalaman bekerja di sektor non-pertanian.

d. Kondisi pekerjaan yang lebih baik dibandingkan kondisi pekerjaan di bidang pertanian.

3. Terbukanya peluang untuk bekerja di sektor non-pertanian dengan persentase $66,67 \%$, dikarenakan tersedianya peluang bekerja di sektor non-pertanian dengan berbagai pilihan pekerjaan dibandingkan saat bekerja di sektor pertanian.

\section{Saran}

Agar peralihan tenaga kerja dari sektor pertanian ke sektor non-pertanian tidak memunculkan permasalahan, maka:

1. Pemerintah setempat perlu membatasi penggunaan lahan pertanian untuk dijadikan lahan non-pertanian.

2. Perlu dikembangkan teknologi pertanian yang mampu mengikat daya tarik petani agar tetap dapat bertahan di sektor pertanian. 


\section{DAFTAR PUSTAKA}

Alagukannan, G., Rajkala. A., Raja Joslin, Y., and Thirumalaivasan. M. 2016. A Study on Occupational Mobility of Farmers of Ariylaur District of Tamil Nadu and Measures to Lessen this Iniquity. International Journal of Humanities and Social Science Invention. ISSN (Online): 2319 - 7722, ISSN (Print): 2319 - 7714.. Volume 5 Issue 11 November. 2016. PP.12-15. Diakses tanggal 29 Januari 2018. From www.ijhssi.org

Koran, Kompas, 20 Juni 2018. Urbanisasi: Otomatisasi jasi Kendala Serapan Pekerja. Pertanian ditinggalkan. Diakses tanggal 20 Juni 2018. Dari https://kompas.id/baca/ metro/2018/06/ 20/otomatisasi-jadi-kendalaserapan-pekerja.

Noragawati, L. 2002. Faktor Penyebab Pergeseran Tenaga Kerja Dari Sektor pertanian Ke Sektor Non Pertanian Pada Masyarakat Desa Telukpinang Kecamatan Ciawi Kabupaten Bogor. IPB (Bogor Agricultural University). Diakses tanggal 10 April 2018. Dari Repository.ipb.ac.id.
Pesik, C. S., Kapantow, G. H., \& Katiandagho, T. M. 2016. Faktor-faktor Penyebab Pergeseran Tenaga Kerja Sektor Pertanian ke Sektor Non Pertanian di Kecamatan Kalawat, Kabupaten Minahasa Utara. Manado. Agri-Sosioekonomi, Vol.12 No. (3A):67-80. Diakses tanggal 22 Februari 2018. Dari Ejournal.unsrat.ac.id.

Singh, R., \& Gupta, K. 2014. Attitude of male adolescents towars family occupatiom of farming: management perspective for Indian policy makers. Purushartha: A Journal Management Ethics and Spirituality, 6(2). Diakses tanggal 29 Januari 2018. From inflibnet.ac.in.

Soekanto, Soerjono. 2017. Sosiologi Suatu Pengantar (Edisi Revisi). Rajawali Pers. Jakarta.

Suparmoko, M. 2008. Ekonomi Publik, Untuk Keuangan dan Pembangunan Daerah. Andi. Yogyakarta.

Suratiyah, Ken. 2015. Ilmu Usahatani (Edisi Revisi). Penebar Swadaya Grup.

Tanto H. T. 2013. Sistem Bawon Di Desa Mungseng Kecamatan Temanggung Kabupaten Temanggung. Fakultas Ilmu Sosial Universitas Negeri Yogyakarta. Skripsi. Diakses pada tanggal 30 Oktober 2017. Dari Eprints.uny.ac.id. 